\title{
A discussion of the scaling effect in numerical simulation of the extrusion process
}

\author{
Z. Peng, T. Sheppard and X. Velay
}

The main objective of the work of this paper is to study the possibility of using a small scale geometrical model in the numerical simulation of aluminium extrusion. The advantages and shortcomings of the application of the geometrically similar model in FEM simulation are discussed. Thermal-mechanical and metallurgical combined simulations are performed within two tests using geometrically similar models and assessment is made in terms of mechanical and material properties. It was found that small scale simulation could not reproduce most of the important forming parameters of the original process, although it could help to bring about significant savings in computation time.

MST/6169

Keywords: Extrusion, FEM, Temperature, Simulation

The authors are at DEC, Bournemouth University, 12 Christchurch road, Bournemouth, UK (tsheppar@bournemouth.ac.uk). Manuscript received 18 March 2004; accepted 4 June 2004.

(C) 2004 Institute of Materials, Minerals and Mining. Published by Maney on behalf of the Institute.

\section{Introduction}

Currently, computer modelling and simulation of the material forming process has been developed to the point that it may be used to solve industrial problems. It is often treated as a universal tool in all problems of metal forming processes. Taking a general view of the present state of the art in terms of numerical modelling, it appears that the finite element method is most suited to the three dimensional analysis of material forming processes. In fact, the finite element method can take into account practical nonlinearity in the geometry and material properties, besides producing accurate predictions of stress, strain, strain rate and temperature throughout the deforming billet. However, in some cases, this stage is extremely time consuming and there are limitations, which could cause fault in the design process. Physical simulation, in which a scaled down process is adopted, would result in the time spent in design to be significantly reduced. It is therefore of great interest to investigate if a small scale model can be adopted in numerical simulations. The relevant question that is frequently being asked concerns the accuracy between simplified modelling and simulation. ${ }^{1}$ When some simplification (for example, a smaller scale but geometrically similar process) is adopted, will the simulation still be of sufficient accuracy? Can the simplified simulation reproduce most of the important forming parameters of the real process?

It should also be borne in mind that at the present time, the trend of numerical simulation is not only coupled thermally and mechanically, but also combined structurally or metallurgically. By empirical and physical means, a modest degree of prediction of microstructure can now be achieved. Excellent reviews on modelling of static recrystallisation (SRX) have been given by Gottstein et $a l^{2}$ and by Shercliff and Lovatt. $^{3}$ Recently, the inverse method combined with FEM has been adopted to integrate those values of parameters reported in the literature. The FEM is run iteratively until the appropriate value is found to match the experimental measurement. Duan and Sheppard ${ }^{4}$ have used the inverse method to give the parameters for alloy 2014.

In the present paper, the possibility of the application of a small scaled model into numerical simulation of extrusion is discussed. It was found that although the small scale model is effective in saving computing time, there are some serious deviations in the simulation results. This indicates that this method is not suitable for the simulation of aluminium extrusion.

\section{FEM setup}

The composition of the material used in this study is shown in Table 1 and the main simulation tooling is shown in Table 2. Two simulations of rod extrusion were performed and the billet size in run 2 was $2 \cdot 5$ times smaller than that in run 1 , in terms of diameter and length. In these two simulations, the extrusion ratio was 20 , the ram speed was $12.4 \mathrm{~mm} \mathrm{~s}^{-1}$, the initial temperature of the billet was $350^{\circ} \mathrm{C}$ and the container temperature was $50^{\circ} \mathrm{C}$ lower than the billet.

The FEM program, FORGE2 is used in the present study. It is a process simulation tool based on the FEM. The hyperbolic sine function was integrated into the FEM to describe the material behaviour. The constitutive equation can then be written as

$$
\bar{\sigma}=\frac{1}{\alpha} \ln \left[\left(\frac{Z}{A}\right)^{\frac{1}{n}}+\left[\left(\frac{Z}{A}\right)^{\frac{2}{n}}+1\right]^{\frac{1}{2}}\right]
$$

where $\alpha, A, n$ are temperature independent constants. $\bar{\sigma}$ is the flow stress. $Z$ is the Zener-Hollomon parameter and it is written as

$$
Z=\dot{\varepsilon} \exp (\Delta H / G T)
$$

where $\dot{\bar{\varepsilon}}$ is the mean equivalent strain rate, $\Delta H$ is the

Table 1 Chemical composition of 2014 (balance Al)

\begin{tabular}{llllllll}
\hline $\mathrm{Mg}$ & $\mathrm{Si}$ & $\mathrm{Ti}$ & $\mathrm{Cr}$ & $\mathrm{Mn}$ & $\mathrm{Fe}$ & $\mathrm{Cu}$ & $\mathrm{Zn}$ \\
\hline $0.20-0.8$ & $0.50-1.2$ & 0.15 & 0.10 & $0.40-1.2$ & 0.7 & $3.9-5.0$ & 0.25
\end{tabular}

Table 2 Tooling of FEM model (as shown in Fig. 1)

\begin{tabular}{lll}
\hline Run & Billet length, $\mathrm{mm}$ & Billet diameter, $\mathrm{mm}$ \\
\hline 1 & 95 & 75 \\
2 & 38 & 30 \\
\hline
\end{tabular}




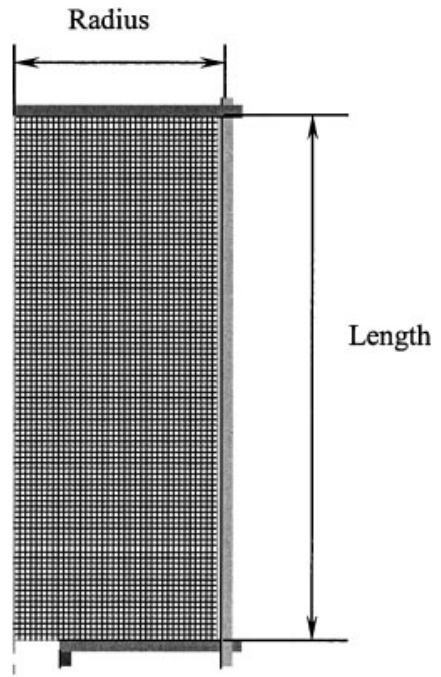

\section{Reference grid pattern (undeformed)}

activation energy, $T$ is the temperature and $G$ is the universal gas constant. For aluminium alloy AA $2014^{5}$

$$
\begin{aligned}
& \Delta H=144408 \mathrm{KJ} \mathrm{mol}^{-1}, \alpha=0.0152 \mathrm{~m}^{2} \mathrm{MN}^{-1}, n=5 \cdot 27, \\
& \ln A=24 \cdot 41 .
\end{aligned}
$$

The Tresca friction law is adopted in the numerical model in this study. This is written in the following form

$$
\tau=-m \frac{\bar{\sigma}}{\sqrt{3}}
$$

where $\tau$ is the friction shear stress, $\bar{\sigma}$ represents the flow stress, $m$ is the friction coefficient, which is in effect a percentage of that which would represent sticking conditions. In this study, because the extrusion temperature is not high, $m=0 \cdot 85$ was adopted. ${ }^{6}$

\section{Discussion}

In the following sections, the thermal-mechanical and the structural combined simulation results of the two runs are compared. The discussion concerning the computation time and material flow pattern were presented first.

\section{MATERIAL FLOW PATTERN}

Previous studies have confirmed that FEM simulation is effective in predicting the material flow pattern. Arentoft et $a l .^{7}$ have studied the material flow in axi-symmetric extrusion with physical and two dimensional FEM simulation. Some studies in multi-hole die extrusion by three dimensional FEM simulation have also been published by the present authors. ${ }^{8}$ In this study, a reference grid pattern was adopted to study the material flow pattern, as shown in Fig. 1. The simulation results of run 1 and run 2 are shown in Figs. 2 and 3 respectively.

As can be seen from Figs. 2 and 3, although the billet sizes are different in these two runs, the simulation results of the material flow pattern are similar. The different deformation areas can be shown clearly in both of these two runs and the predictions correspond well with the experimental results, ${ }^{9}$ which are shown in Fig. 4 . The complete computation time of the first run is about $25 \mathrm{~h}$ while in run 2 , the total time is not more than $15 \mathrm{~h}$. It is evident therefore that the computation time can be significantly saved $(40 \%)$ with a small scale simulation and the simulation result is still approximate compared with

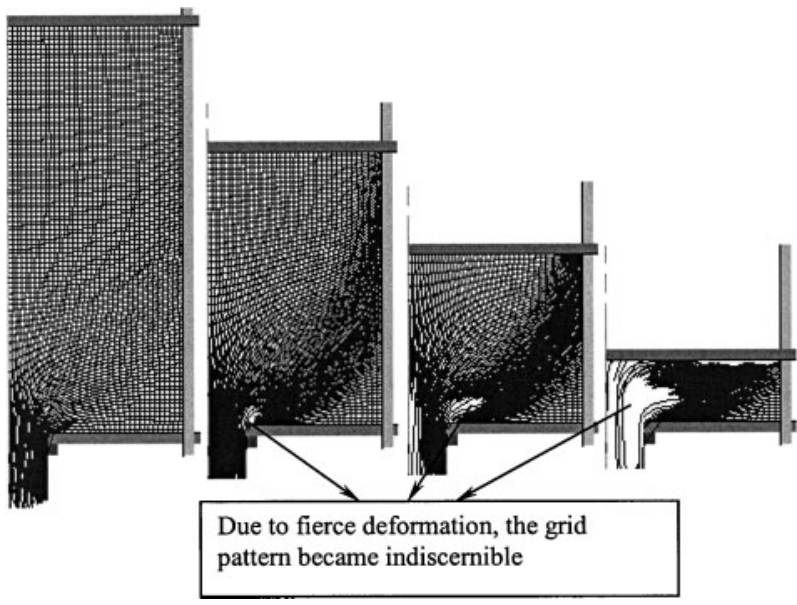

\section{Simulation result using the full size billet}

the material flow pattern of the original process. In fact, it is worth noting that small scale simulation has been used in the field of physical simulation, in which soft materials were adopted in experiments and the cost of design was then significantly saved. ${ }^{2}$ However, the majority of the cases reported in the literature show that the usage of physical modelling is limited to qualitative analyses of the material flow.

It has been pointed out by Arentoft ${ }^{7}$ that the basic problem lies in the transferral of the model experiment results to reality. In the case of extrusion, in which temperature rise is significant and strain rate is quite high, more important factors in addition to the material flow need to be considered, for example, the structure evolution. To ensure accurate results and interpretation, the model and the real process must be similar. For metalworking processes the following important similarity conditions must be created:10,11 geometrical, plastic, frictional, thermal, elastic and dynamic. The fulfilment of all of these conditions is practically impossible. In most cases, the first four conditions are the most important, although they are also perhaps the hardest to fulfil. Therefore, it is essential to determine and select which material properties and process parameters are the most relevant for the purpose of the experiment.

During the process of extrusion, the press load, temperature rise, surface quality and extrudate mechanical properties are the most important factors to be considered. If any simulation is applied in extrusion, it has to be effective in predicting all of the above factors. In the following sections of this study, the analysis results of these forming parameters in the small scale simulation are discussed.

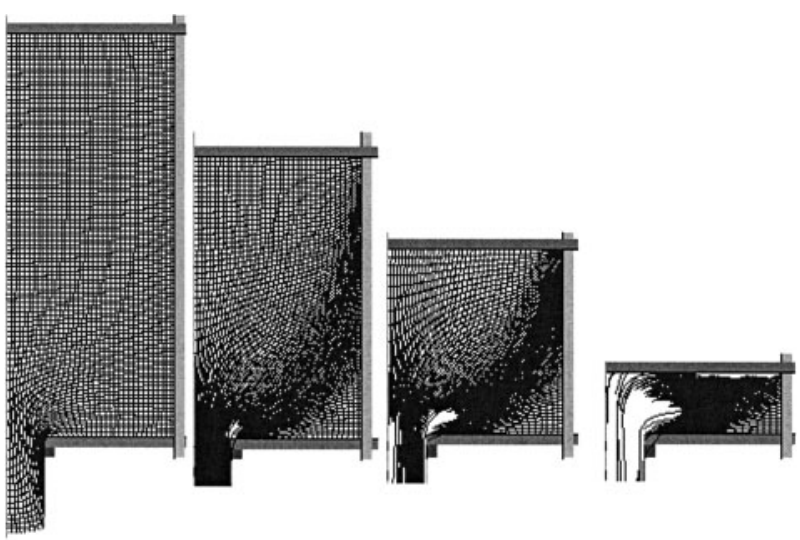

3 Simulation result using the small scale billet 


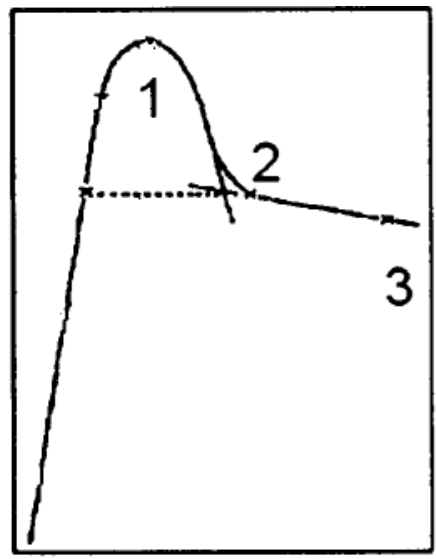

Extrusion stages

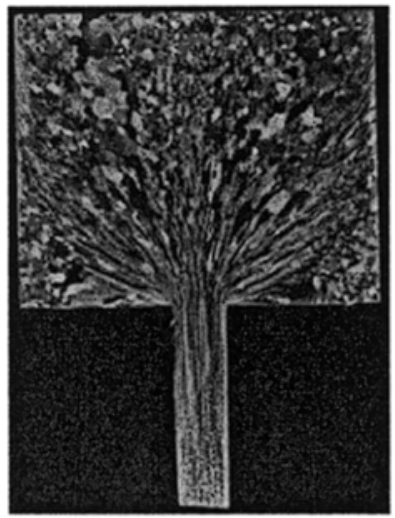

Stage 2

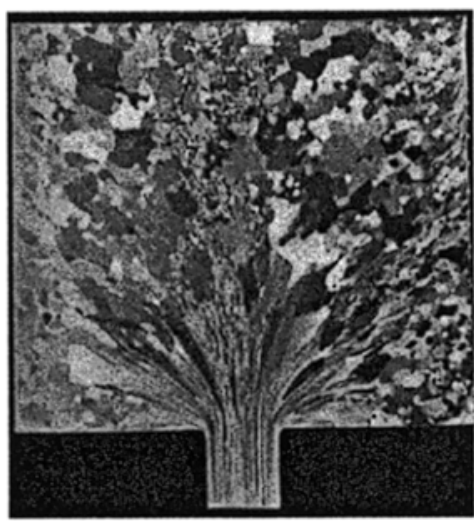

Stage 1

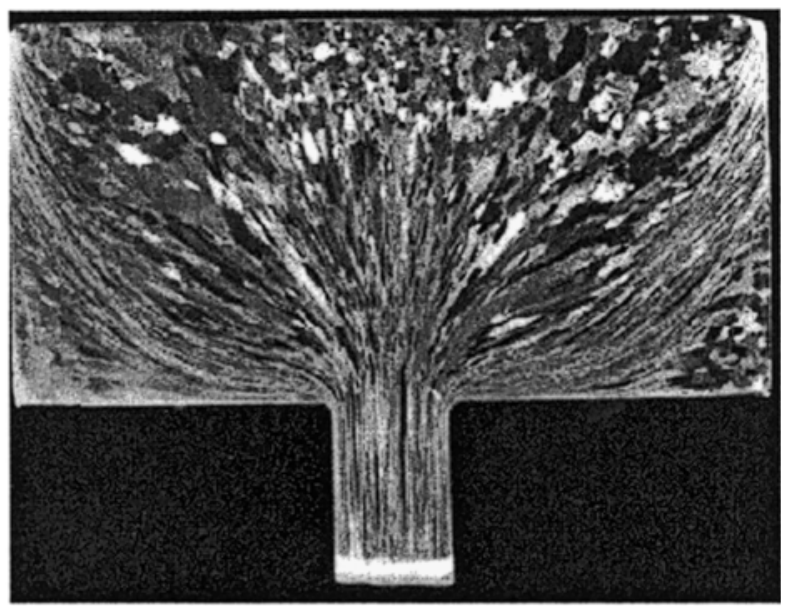

Stage 3

4 Experimental result of the material flow pattern after Tutcher and Sheppard ${ }^{9}$

\section{MECHANICAL AND STRUCTURAL}

\section{SIMULATION RESULTS}

Firstly, the simulated instantaneous strain rate distributions $(\ln (\dot{\varepsilon}))$ in these two runs are compared as shown in Figs. 5 and 6 .

The average strain rates of the whole deformation area calculated by the FEM program and given by the upper bound method ${ }^{12}$ according to equation (4) are shown in Table 3.

$$
\overline{\dot{\varepsilon}}=\frac{6 V_{\mathrm{B}} D_{\mathrm{B}}^{2}(0 \cdot 171+1 \cdot 86 \ln R) \tan (38 \cdot 7+6 \cdot 9 \ln R)}{D_{\mathrm{B}}^{3}-D_{\mathrm{E}}^{3}}
$$

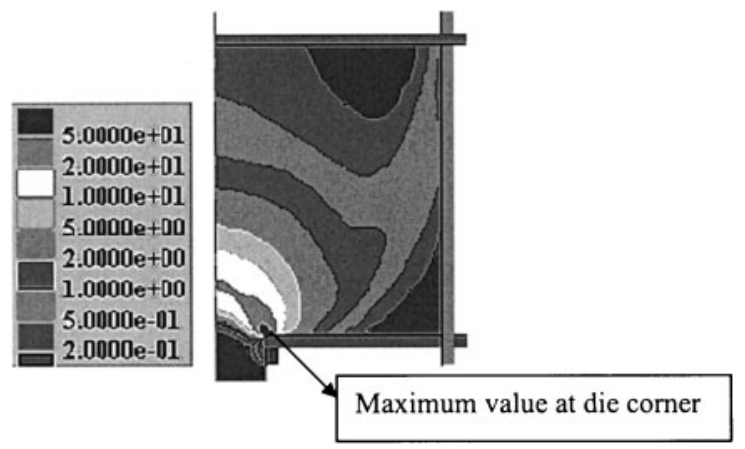

5 The distribution of the $\ln (\dot{\varepsilon})$ in the billet with full size (run 1)

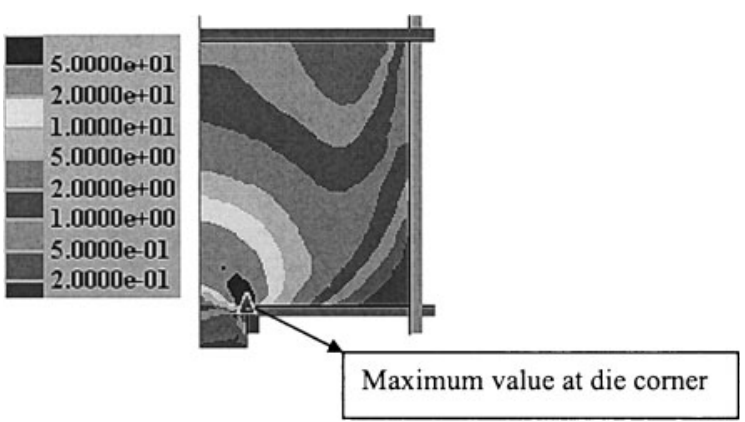

6 The distribution of the $\ln (\dot{\varepsilon})$ in the small scale billet (run 2)

where $V_{\mathrm{B}}$ is the ram speed, $D_{\mathrm{B}}$ is the billet diameter, $D_{\mathrm{E}}$ is the extrude diameter and $R$ is the extrusion ratio.

However, in the process of extrusion, the main deformation occurred at the area near the die orifice as shown in Figs. 5 and 6 . The average strain rate of the whole

Table 3 Average strain rate of extrusion

\begin{tabular}{llll}
\hline & $\begin{array}{l}\dot{\bar{\varepsilon}} \text { of the whole } \\
\text { deformation area } \\
\text { calculated by } \\
\text { FEM, s }\end{array}$ & $\begin{array}{l}\dot{\bar{\varepsilon}} \text { given by } \\
\text { equation }(4), \\
\mathrm{s}^{-1}\end{array}$ & $\begin{array}{l}\text { Average strain } \\
\text { rate in the area } \\
\text { with } \ln (\dot{\varepsilon})>1, \\
\mathrm{~s}^{-1}\end{array}$ \\
\hline 1 & 6.57 & 5.6 & 28.3 \\
2 & 15.1 & 14.4 & 31.7 \\
\hline
\end{tabular}




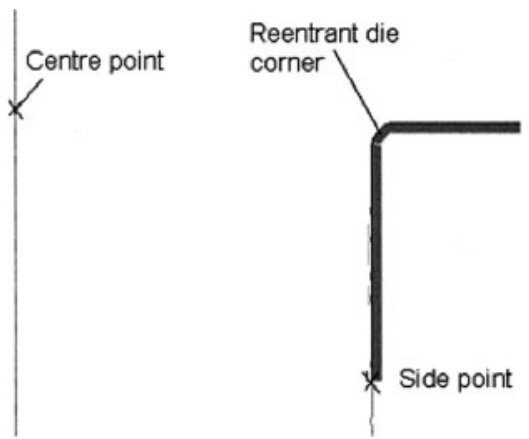

\section{The deformation area}

deformation area could not reflect the true condition of the process, so the average strain rate of the area with $\ln (\dot{\varepsilon})>1$ was calculated and the results are also shown in Table 3.

It can be seen from Figs 5 and 6, and Table 3 that the strain rate, either in the terms of 'average' or 'instant', is much higher in the small scale simulation than that predicted in run 1 . So, it could be said that the small scale simulation could not reflect the original deformation properly in the terms of stain rate.

The temperature rise during extrusion was also studied. In extrusion, the temperature distribution in the billet is a critical process variable, affecting extrusion pressure, speed, surface finish and mechanical properties. Extrusion exit temperature also determines the surface finish and shape dimensions. The temperature rise is actually more significant than most of the other metal forming process. The simulation results of the exit temperatures of runs 1 and 2 are shown in Figs. 8 and 9 respectively. The side temperature and the centre temperature are extracted from the side point and the centre point, which are shown in Fig. 7.

The main difference concerning the temperature rise in these two runs can be concluded in two points.

(i) The maximum temperature. In the present study, the extrusions were carried to the end of the billet length. It should be borne in mind that in real situations, extrusion is normally stopped when the billet has extruded to about $90 \%$ of its length, which is marked in Figs. 8 and 9 with a vertical line. It can be seen from Figs. 8 and 9 that the maximum temperature on the surface of the extrudate in run 1 is $475^{\circ} \mathrm{C}$ while it is $466^{\circ} \mathrm{C}$ in run 2 . The maximum temperature in the centre of the extrudate in run 1 is $432^{\circ} \mathrm{C}$ while it is $447^{\circ} \mathrm{C}$ in run 2

(ii) The temperature gradient along the transverse direction (between the surface and the centre of the extrudate). In run 1 , the temperature difference

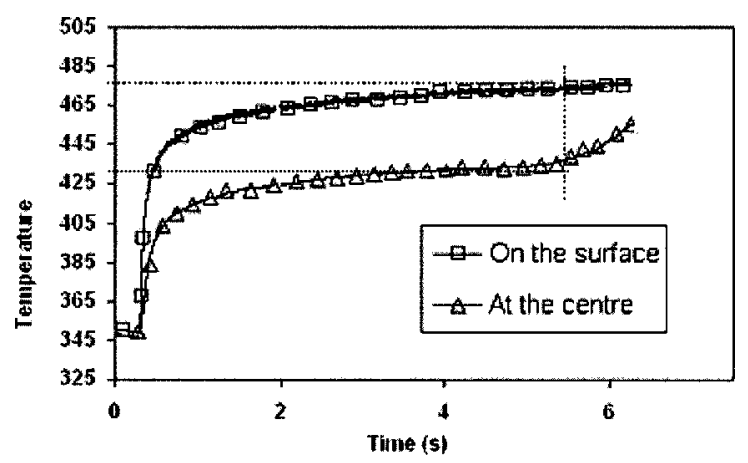

8 Temperature rise at the full size billet (run 1, temperature in ${ }^{\circ}$ )

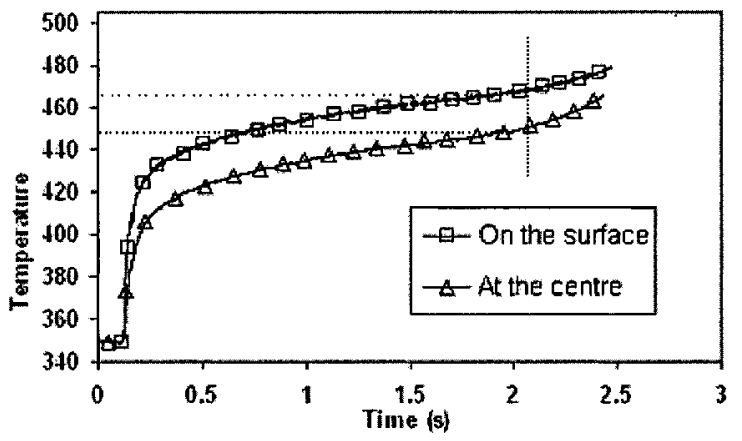

9 Temperature rise at the small scale billet (run 2, temperature in ${ }^{\circ}$ C)

between the surface and the centre is maintained at $43^{\circ} \mathrm{C}$ while it is only $19^{\circ} \mathrm{C}$ in run 2 . This is obviously a large difference.

As can be seen from the discussion above, although the geometrical conditions are similar in these two runs, there is no similar or proportional result concerning the exit temperature. The small scale simulation failed to predict the correct temperature distribution, especially in the die orifice area. It is well known that the exit temperature depends on the initial billet temperature, the magnitude of the work carried out during extrusion, and how this is divided between the work needed to overcome friction and the heat losses to the tooling. ${ }^{13}$ The geometrically similar conditions cannot guarantee that the simulation result will be correct.

Because the material structure (subgrain size and recrystallised grain size) is closely related to the strain rate and the temperature, the small scale simulation will also give incorrect predictions.

\section{SIMULATION RESULTS OF THE STRUCTURAL DEVELOPMENT}

First, the models for the structural simulation are introduced below. The subgrain size is the most commonly used parameter in the study of aluminium extrudate structures. The subgrain size can be related to the temperature compensated strain rate $Z$ and therefore the process condition for alloy AA 2014 by $^{12}$

$$
d^{-1}=0.096 \ln Z-1.747
$$

During aluminium extrusion, the extrudate often suffers recrystallisation. The Johnson - Mehl-Avrami-Kolmogorov equation $(\mathrm{JMAK})^{14}$ predicts the relationship between the volume fraction recrystallised $(X v)$ and the holding time $(t)$ and is generally represented as

$$
X v=1-\exp \left\{-0.693\left(\frac{t}{t_{50}}\right)^{\mathrm{k}}\right\} \text {. }
$$

where $t$ is annealing time, $k$ is the Avrami exponent with a commonly reported value of $2, t_{50}$ is the time to $50 \%$ recrystallisation. Previous studies ${ }^{14}$ have shown that the physical models describe the experimental results well for uniform processing conditions. More recent studies ${ }^{15,16}$ have confirmed that the physical model will give better computed results than the empirical model in the simulation of aluminium extrusion. In this study, the physical model is adopted.

In equation (7), $t_{50}$ is calculated based on the stored energy $P_{\mathrm{D}}$ and the density of recrystallisation nuclei $N_{\mathrm{V}}{ }^{15}$

$$
t_{50}=\frac{C}{M_{\mathrm{GB}} P_{\mathrm{D}}}\left(\frac{1}{N_{\mathrm{V}}}\right)^{1 / 3}
$$

where $C$ is a calibration constant. $M_{\mathrm{GB}}$ is the boundary 


\section{Table 4 The predicted material structures}

\begin{tabular}{|c|c|c|c|c|c|c|}
\hline \multirow[b]{2}{*}{ Run } & \multirow[b]{2}{*}{ Predicted subgrain size, $\mu \mathrm{m}$} & \multicolumn{2}{|c|}{ Predicted grain size, $\mathrm{mm}$} & \multirow[b]{2}{*}{ Experimental subgrain size, $\mu \mathrm{m}$} & \multicolumn{2}{|c|}{ Experimental grain size, $\mathrm{mm}$} \\
\hline & & Centre & Edge & & Centre & Edge \\
\hline $\begin{array}{l}1 \\
2\end{array}$ & $\begin{array}{l}1 \cdot 75 \\
2 \cdot 26\end{array}$ & $\begin{array}{l}0.294 \\
0.250\end{array}$ & $\begin{array}{l}0.273 \\
0.232\end{array}$ & $1 \cdot 43 \pm 0.25$ & $0.321 \pm 0.04$ & $0.266 \pm 0.04$ \\
\hline
\end{tabular}

mobility. $N_{\mathrm{V}}$ is the density of nucleation sites and defined as

$$
N_{\mathrm{V}}=\left(C_{\mathrm{d}} / \delta^{2}\right) S_{\mathrm{V}}(\varepsilon)
$$

where $C_{\mathrm{d}}$ is a further calibration constant, $C_{\mathrm{d}}=1.48 \times 10^{-4}$. $\delta$ is the subgrain size, $S_{\mathrm{V}}$ is the grain boundary area per unit volume

$$
S_{\mathrm{V}}(\varepsilon)=\left(2 / d_{0}\right)[\exp (\varepsilon)+\exp (-\varepsilon)+1]
$$

$d_{0}$ is the grain size after homogenisation. The stored energy $P_{\mathrm{D}}$ is approximated by

$$
P_{\mathrm{D}}=0.5 G\left(\frac{b C_{\delta}}{\delta}\right)^{2}+0 \cdot 05 G \frac{b}{\delta}
$$

where $C_{\delta}$ is a constant of typical value of the order $5, G$ is the shear modulus, $b$ is the Burgers vector, $d_{0}$ is the initial grain size.

Selecting $C_{\delta}=5$ then the second terms will totally dominate as long as $\delta>0.4 \mu \mathrm{m} . G=2.05 \times 10^{10} \mathrm{~Pa}, b=$ $2 \cdot 86 \times 10^{-10} \mathrm{~m}^{16}$ In Furu's study, ${ }^{17} C /\left(M_{\mathrm{GB}} P_{\mathrm{D}}\right)=$ $1.2 \times 10^{5}$ when the strain and strain rate are at high values.

For site saturated nucleation, the recrystallised grain size $d_{\text {rex }}$ is simply calculated from nucleation density as

$$
d_{\mathrm{rex}}=D N_{\mathrm{V}}^{-1 / 3} \text {. }
$$

where $D$ is a constant $(2 \cdot 347){ }^{18}$

Although this model is still at an early stage, the modest prediction of the $t_{50}$ and recrystallised grain size can be achieved. The calculation results are shown in Table 4.

As can be seen from Table 4, the simulation with the original billet size gave reasonable results while the small scale simulation gave relatively deviant results compared with the experimental results. The small scale simulation proved to give incorrect results in material structural simulation.

\section{Conclusion}

It has been confirmed in this study that a small scale simulation is capable of providing limited qualitative information of the extrusion process, for example, the material flow pattern.
The small scale simulation fails to accurately predict the correct temperature distribution, especially in the die orifice area.

The small scale simulation proved to give incorrect results in material structure (i.e. subgrain sizes and recrystallised grain size).

\section{References}

1. B. P. P. A. GOUVEIA, J. M. C. RODRIGUES, P. A. F. MARTINS and N. BAY: J. Mater. Process. Technol., 2001, 112, 244-251.

2. H. ARETZ, R. LUCE, M. WOLSKE, R. KOPP, M. GOERDELER, V. MARX, G. POMAnA and G. GOTTSTEIN: Modell. Simulat. Mater. Sci. Eng., 2000, 8, 881-891.

3. T. FURU, H. R. SHERCLIFF, G. J. BAXTER and C. M. SELlARS: Acta Materialia, 1999, 47, 2377-2389.

4. X. DUAN and T. SHEPPARD: Modell. Simulat. Mater. Sci. Eng. 2002, 10, 363-380.

5. T. SHEPPARD and A. JACKSON: Mater. Sci. Technol., 1997, 13, $203-209$.

6. I. FLITTA and T. SHEPPARD: Mater. Sci. Technol., 2003, 19, 837846.

7. M. ARENTOFT, Z. GRONOSTAJSKI, A. NIECHAJOWICZ and T. WANHeIM: J. Mater. Process. Technol., 2000, 106, 2.

8. Z. PENG and T. SHEPPARD: Mater. Sci. Eng. A, 2004, 367, 329342.

9. M. G. TUTCHER and T. SHEPPARD: Metals Technol., 1980, 7, 488493.

10. T. WANHEIM: 4th Conf. on 'Mechanical design and production', Cairo, Egypt, December 1988, Cairo University.

11. H. Ferguson: Adv. Mater. Process., 1993, 4, 33-36.

12. T. SHEPPARD: Extrusion of aluminium alloys, 142; 1999 , Dordrecht, Kluwer.

13. T. SHEPPARD: Mater. Sci. Technol., 1999, 15, 459-463.

14. T. FURU, H. R. SHERCLIFF, C. M. SELLARS and M. F. ASHBY: Mater. Sci. Forum, 1996, 217-222, Vol. 1, 453-458.

15. E. NES, H. E. VATNE, O. DAALAND, T. FURU, R. ORSUND and K. MARTHINSEN: 4th Int. Conf. on 'Aluminium alloys: their physical and mechanical properties' (ICAA4), Atlanta, GA, USA, September 1994, Vol. 3, 18-49; 1994, Atlanta, GA, Georgia Institute of Technology.

16. X. DUAN and T. SHEPPARD: Computat. Mater. Sci., 2003, 27, $250-258$.

17. T. FURU, H. R. SHERCLIFF, G. J. BAXTER and C. M. SEllarS: Acta Materialia, 1999, 47, 2377-2389.

18. C. M. SEllars and Q. ZHU: Mater. Sci. Eng. A: Struct. Mater.. Propert., Microstruct. Process., 2000, 280, $1-7$. 